\title{
FORAGER POLYMORPHISM AND FORAGING ECOLOGY IN THE LEAF-CUTTING ANT, ATTA COLOMBICA
}

\author{
By JAMES K. WETTERER \\ Center for Environmental Research and Conservation \\ Columbia University \\ 1200 Amsterdam Avenue \\ New York, NY 10027
}

\begin{abstract}
I compare forager size and foraging selectivity of the leaf-cutting ant Atta colombica and that of its close relative Atta cephalotes. In both species, larger foragers cut fragments of greater mass and area, and at vegetation sources of greater specific density (mass/area). However, the size-range of A. colombica foragers $(1.5-56.8 \mathrm{mg})$ was wider than the range typical for $A$. cephalotes $(1.4-32.1 \mathrm{mg})$. In A. colombica, the maxima workers (24-60 mg) commonly participate in foraging, making up $13 \%$ of all foragers in this study and in a previous study. In contrast, $A$. cephalotes maxima workers $(24-100 \mathrm{mg}$ ) rarely forage (less than $1 \%$ of all foragers in two previous studies), but instead serve primarily as soldiers defending the nest. Thus, A. colombica maxima workers are smaller and do not appear to be so specialized as soldiers as are A. cephalotes maxima workers. The broader size-range of workers participating in foraging appears to allow $A$. colombica to exploit a wider range of resources than $A$. cephalotes, including tougher, denser vegetation and fallen fruits.
\end{abstract}

\section{INTRODUCTION}

Leaf-cutting ants of the genus Atta are the most important agricultural pests of the New World tropics (Wilson, 1986). Three species of Atta occur in Central America: Atta sexdens (L.), Atta colombica Guérin, and Atta cephalotes (L.) (Weber 1972). A. sexdens is fairly easy to distinguish from the other two Atta species using morphological characters (Weber 1968, 1969; Mackay and

Manuscript received 17 April 1995. 
Mackay, 1986). A. colombica and A. cephalotes, however, are very similar in appearance and often difficult to distinguish. Emery (1913) considered A. colombica to be a subspecies of $A$. cephalotes, saying that the differences between the two taxa were simply related to the degree of polymorphism, with A. colombica having soldiers that were smaller than A. cephalotes soldiers. Later, however, Emery (1922) separated A. colombica and A. cephalotes as two distinct species.

Currently, the most reliable morphological character for distinguishing $A$. colombica workers from A. cephalotes workers is the luster of their integument: $A$. colombica workers are entirely matte, while $A$. cephalotes workers have shiny areas, particularly on the head and pronotum (Weber 1968, 1969; J. Longino, pers. comm.). Another character often used for distinguishing these two species in the field is that A. colombica is the only species of Atta reported in the literature to have external refuse dumps for exhausted fungus garden substrate (Haines, 1978). The presence of an external refuse dump indicates that the A. "cephalotes" colony studied by Hodgson (1955) in Panama was almost certainly an A. colombica colony.

A. colombica is known from Colombia, Panama, Costa Rica, and Guatemala, whereas A. cephalotes is widespread from Brazil to Mexico (Kempf, 1972; Weber, 1972). Where colonies of these two species of leaf-cutters come into direct contact, prolonged territorial battles may ensue (J. Longino, pers. comm.). Several studies have compared the ecology of A. colombica and A. cephalotes. Weber (1969) described both A. colombica and A. cephalotes as "forest or forest-grassland ecotone species," stating that "the ecological relations between cephalotes and colombica remain to be determined." Several authors found that when the two species occur together in the same area, A. colombica tends to be more common in younger forest, with $A$. cephalotes more common in the older forest (Rockwood, 1973; Feener and Moss, 1990; Orr, 1992). Mackay and Mackay (1986) stated that A. colombica usually occurs in drier areas, while A. cephalotes is found in a diversity of habitats. Rockwood (1973), however, proposed that A. colombica occurs in wetter areas than $A$. cephalotes.

The foraging ecology of $A$. colombica and A. cephalotes appears to be fairly similar. Mature colonies of both species primarily 
attack the leaves of trees, preferring the younger, softer leaves (Shepherd, 1985; Vasconcelos, 1990). My preliminary observations, however, indicate that in A. colombica the largest "maxima" workers $(24-60 \mathrm{mg}$ ) regularly participate in foraging, whereas $A$. cephalotes maxima workers $(24-100 \mathrm{mg})$ seldom forage. In thr present study, I examine forager size and foraging selectivity of $A$. colombica, and evaluate ecological similarities and differences between A. colombica and A. cephalotes.

\section{METHODS}

I conducted this study with several large colonies of Atta colombica on Barro Colorado Island (BCI), Panama in July 1992. In addition, I considered more informal observations of $A$. colombica that I made on BCI in August 1990.

At the main A. colombica study colony (colony A), I collected 25 laden ants from each of three foraging trails in order to evaluate the match between forager mass and vegetation resource types. I selected foraging trails coming from three very different vegetation sources: 1) a tree with thin, soft leaves, 2) a tree with tough, veiny leaves, and 3) a crop of thick fig leaf stipules scattered on the forest floor.

I placed each ant with her load in a separate $2.5 \mathrm{ml}$ vial, and anesthetized the ants by placing the vials in a refrigerator for several minutes. I then measured the mass of each ant $\left(m_{\mathrm{A}}\right)$ and each load $\left(m_{\mathrm{L}}\right)$ to the nearest $0.1 \mathrm{mg}$ on a Mettler balance. In addition, I measured the area $(\alpha)$ of each leaf and stipule fragment using a Licor area meter.

From mass and area data I calculated the following measures: burden $(\beta)=$ the ratio of load mass to ant mass $\left(m_{\mathrm{L}} / m_{\mathrm{A}}\right)$; individual load specific density $(\delta)=m_{\mathrm{L}} / \alpha$; overall specific density $(D)$ for each vegetation source $=$ the sum of the load masses divided by the sum of the 25 areas.

To normalize distributions, I performed all regression analyses on log-transformed data. I calculated "residual log load mass" values by subtracting the log load mass values predicted by the log ant mass versus log load mass regressions (for the combined data from all 75 ants) from the actual observed log load mass values. I calculated "residual log load area" values in an analogous manner. 
At a second A. colombica colony (colony B) where foragers along one trail were carrying whole berries and berry fragments, I collected 10 ants laden with whole berries. I did not collect foragers with berry fragments.

At several additional A. colombica colonies on BCI, I collected the largest unladen workers I could find (along trails and exiting disturbed nests) in an effort to determine the maximum worker size for this species. I weighed each of these ants and measured their head widths under a dissecting microscope using an ocular micrometer. I also measured head widths of A. colombica and $A$. cephalotes specimens in the collection at the Museum of Comparative Zoology (MCZ) at Harvard University. Any specimens in the MCZ collection that appeared to be incorrectly identified I sent to John T. Longino for verification. A. colombica voucher specimens from this study have been deposited in the MCZ.

\section{RESULTS}

Forager mass and load size

Overall, the A. colombica foragers from colony A $(n=75$ : three collections of 25 ants each) weighed from 1.5 to $56.8 \mathrm{mg}$, a 38 fold range of mass (Table 1). Ten of the 75 foragers (13\%) weighed more than $24 \mathrm{mg}$ (Table 1).

Specific density varied greatly among the three vegetation sources attacked by colony A (Table 1 ). The fragments harvested from the thin leaf tree had an overall specific density $(D)$ of 0.12 $\mathrm{mg} / \mathrm{mm}^{2}$ (range of specific density for individual fragments, $\delta=$ 0.104 to $0.155 \mathrm{mg} / \mathrm{mm}^{2}$ ), whereas the fallen fig leaf stipules had an overall specific density of $0.42 \mathrm{mg} / \mathrm{mm}^{2}$ (range of $\delta=0.263$ to $0.726 \mathrm{mg} / \mathrm{mm}^{2}$ ). The fragments from the tree with tough veiny leaves consisted of 22 leaf fragments and 3 leaf stipule fragments and were variable in specific density (Table 1 ; overall $D=0.28$ $\mathrm{mg} / \mathrm{mm}^{2}$, range of $\delta$ for 22 leaf fragments $=0.187$ to 0.361 $\mathrm{mg} / \mathrm{mm}^{2}$ and for the 3 stipule fragments $=0.351$ to 1.206 $\mathrm{mg} / \mathrm{mm}^{2}$ ).

Mean forager mass also varied greatly among the three vegetation sources (Table 1), from $4.9 \mathrm{mg}$ at the thin leaf tree to $20.6 \mathrm{mg}$ at the fig leaf stipule source. Mean ant mass correlated positively with specific density (Table 1). 
Table 1. Atta colombica forager mass at different sources compared with data from earlier studies with Atta cephalotes. A. colombica: foragers from one colony (colony A) collected coming from three different vegetation sources (thin leaf tree, veiny leaf tree, and fallen fig stipules), from a second colony (colony B) carrying whole berries, and data from Lighton et al. (1987). The data from the veiny leaf tree are further divided into data for ants with leaf fragments and for ants with leaf stipule fragments. Overall specific density ( $D=$ total mass/total area), mean and range of ant mass $\left(m_{\mathrm{A}}\right.$ in $\left.\mathrm{mg}\right)$, coefficient of variation of forager mass $(\mathrm{CV}=\operatorname{mean} / \mathrm{SD})$, and percent of foragers larger than $24 \mathrm{mg}(\%>24)$. A. cephalotes: foraging from two earlier field studies (Wetterer 1990a; 1994). In Wetterer (1990a) collections were made during the day and night along a single trail $(\mathrm{n}=400$ for each) and coming down a grapefruit tree $(\mathrm{n}=150$ for each). In Wetterer (1994) collections were made along trails coming down 18 trees $(n=50$ for each tree; total $n=900)$.

\begin{tabular}{lrccccr}
\hline \multicolumn{1}{c}{ Source } & $\mathrm{n}$ & $\begin{array}{c}\text { Density } \\
\left(\mathrm{mg} / \mathrm{mm}^{2}\right)\end{array}$ & mean $\pm \mathrm{SD}$ & rorager Mass $(\mathrm{mg})$ & $\mathrm{CV}$ & $\%>24$ \\
\hline Atta colombica & & & & & & \\
Colony A (total) & 75 & $0.12-0.42$ & $11.0 \pm 12.3$ & $1.5-56.8$ & 1.11 & 13 \\
$\quad$ thin leaf tree & 25 & 0.12 & $4.9 \pm 2.6$ & $1.5-13.1$ & 0.54 & 0 \\
$\quad$ veiny leaf tree & 25 & 0.28 & $7.5 \pm 5.2$ & $3.1-27.2$ & 0.69 & 4 \\
$\quad$ leaf & 22 & 0.23 & $6.1 \pm 2.0$ & $3.1-11.5$ & 0.33 & 0 \\
$\quad$ stipule & 3 & 0.48 & $18.2 \pm 9.6$ & $8.1-27.2$ & 0.53 & 33 \\
$\quad$ fig stipule & 25 & 0.42 & $20.6 \pm 16.8$ & $4.3-56.8$ & 0.82 & 36 \\
Colony B: berries & 10 & - & $29.5 \pm 13.1$ & $16.8-52.7$ & 0.45 & 40 \\
Lighton et al. & 154 & - & $15.2 \pm 7.1$ & $3.6-35.6$ & 0.47 & 13 \\
& & & & & & \\
Atta cephalotes & & & & & & \\
Wetterer & 2000 & $0.15-0.37$ & $4.2-11.1$ & $1.4-32.1$ & $0.31-0.73$ & 0.4 \\
\hline
\end{tabular}

Combining data from all 75 ants, I found that logarithmic relationships between ant mass $\left(m_{\mathrm{A}}\right)$ and load mass $\left(m_{\mathrm{L}}\right)$, load area $(\alpha)$, and specific density $(\delta)$ were all significantly increasing functions (Fig. 1; $\log m_{\mathrm{L}}=0.09+1.16 \log m_{\mathrm{A}}, \mathrm{R}^{2}=0.67, \mathrm{n}=75 ; P$ $<0.001$; Fig. $2 ; \log \alpha=1.08+0.74 \log m_{\mathrm{A}}, \mathrm{R}^{2}=0.42, \mathrm{n}=75, P$ $<0.001$; Fig. $3 ; \log \delta=-0.99+0.42 \log m_{\mathrm{A}}, \mathrm{R}^{2}=0.36, \mathrm{n}=75, P$ $<0.001)$. Larger ants cut fragments of greater mass, area, and density.

Examining each vegetation source separately, there was a significant $(P<0.05)$ relationship between ant mass and load mass and between ant mass and load area at all three sources (Table 2). There was no significant relationship between specific density and ant mass at the thin leaf tree or the fig stipules (thin leaf: $\log \delta=$ $-0.92+0.04 \log m_{\mathrm{A}}, \mathrm{R}^{2}=0.03, \mathrm{n}=25, P>0.05$; stipules: $\log \delta=$ $\left.-0.38+0.01 \log m_{\mathrm{A}}, \mathrm{R}^{2}=0.00, \mathrm{n}=25, P>0.05\right)$. There was a 


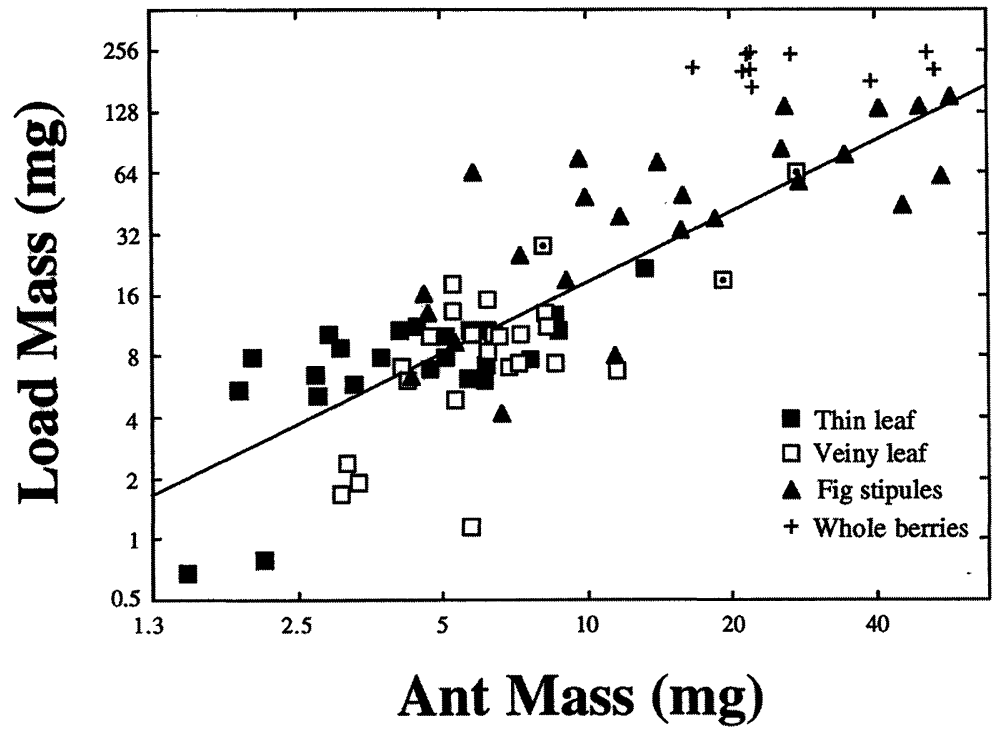

Figure 1. Load mass selection by Atta colombica foragers. The logarithmic relationship between ant mass $\left(m_{\mathrm{A}}\right.$ in $\left.\mathrm{mg}\right)$ and load mass $\left(m_{\mathrm{L}}\right.$ in $\left.\mathrm{mg}\right)$. The line is the least squares linear regression for the 75 foragers from colony $\mathrm{A}$ with vegetation fragments (values for foragers from colony B carrying berries not included in regression calculation). Equation given in text. Closed squares $=$ thin leaf tree; open squares $=$ veiny leaf tree ( with dot $=$ leaf stipule); closed triangles $=$ fig stipules; crosses $=$ whole berries.

Table 2. Load size for Atta colombica foragers from colony A at three different vegetation sources (thin leaf, veiny leaf, and fig stipule). Burden $\left(\beta=m_{\mathrm{L}} / m_{\mathrm{A}}\right)$, residual $\log \operatorname{load}$ mass $(\log \mathrm{mL})$, and residual $\log \operatorname{load}$ area $(\log \alpha)$. For each collection, $\mathrm{n}=25$.

\begin{tabular}{lcrrrrrr}
\hline Source & $\begin{array}{c}\text { Burden } \\
\text { mean } \pm 1 \mathrm{sd}\end{array}$ & $\log m_{\mathrm{L}}$ regression & $\mathrm{R}^{2}$ & $\begin{array}{c}\text { residual } \\
\log m_{\mathrm{L}}\end{array}$ & $\log \alpha$ regression & $\mathrm{R}^{2}$ & $\begin{array}{c}\text { residual } \\
\log \alpha\end{array}$ \\
\hline thin leaf & $1.8 \pm 0.9$ & $0.2+0.9 \log m_{\mathrm{A}}$ & 0.44 & 0.002 & $1.2+0.9 \log m_{\mathrm{A}}$ & 0.44 & 0.175 \\
veiny leaf & $1.5 \pm 0.8$ & $-0.1+1.2 \log m_{\mathrm{A}}$ & 0.49 & -0.125 & $0.8+0.9 \log m_{\mathrm{A}}$ & 0.36 & -0.170 \\
fig stipule & $3.2 \pm 2.2$ & $0.5+0.9 \log m_{\mathrm{A}}$ & 0.55 & 0.123 & $0.9+0.9 \log m_{\mathrm{A}}$ & 0.50 & -0.004 \\
\hline
\end{tabular}

significant relationship between specific density and ant mass at the tree with veiny leaves $\left(\log \delta=-0.87+0.33 \log m_{\mathrm{A}}, \mathrm{R}^{2}=0.17\right.$, $\mathrm{n}=25, P<0.05$ ), primarily because the three foragers with dense leaf stipule fragments were much larger than the 22 foragers with leaf fragments (Table 1). 
Burden $\left(\beta=m_{\mathrm{L}} / m_{\mathrm{A}}\right)$ ranged from 0.2 to 11.0 . Of the three vegetation sources, mean burden was lowest at the veiny leaf source and highest at the fig leaf stipules (Table 2). The load mass cut by ants of a given size varied among the three vegetation sources; the mean residual log load mass was lowest at the very thin leaf source and highest at the stipules (Table 2). The fragment area cut by ants of a given size also varied among the three sources; the mean residual log load area was lowest at the veiny leaf source and highest at the thin leaf (Table 2). At all three sources, the workers with loads of the lowest residual area values were among the smallest workers attacking the source (Fig. 2).

Foragers with whole berries

At A. colombica colony B, the 10 foragers that I collected carrying whole berries ranged from 16.8 to $52.7 \mathrm{mg}$ (Table 1). Four of these foragers weighed more than $24 \mathrm{mg}$; nine weighed more than $20 \mathrm{mg}$ (Fig. 1). The mass of the berries ranged from 177.9 to 247.8

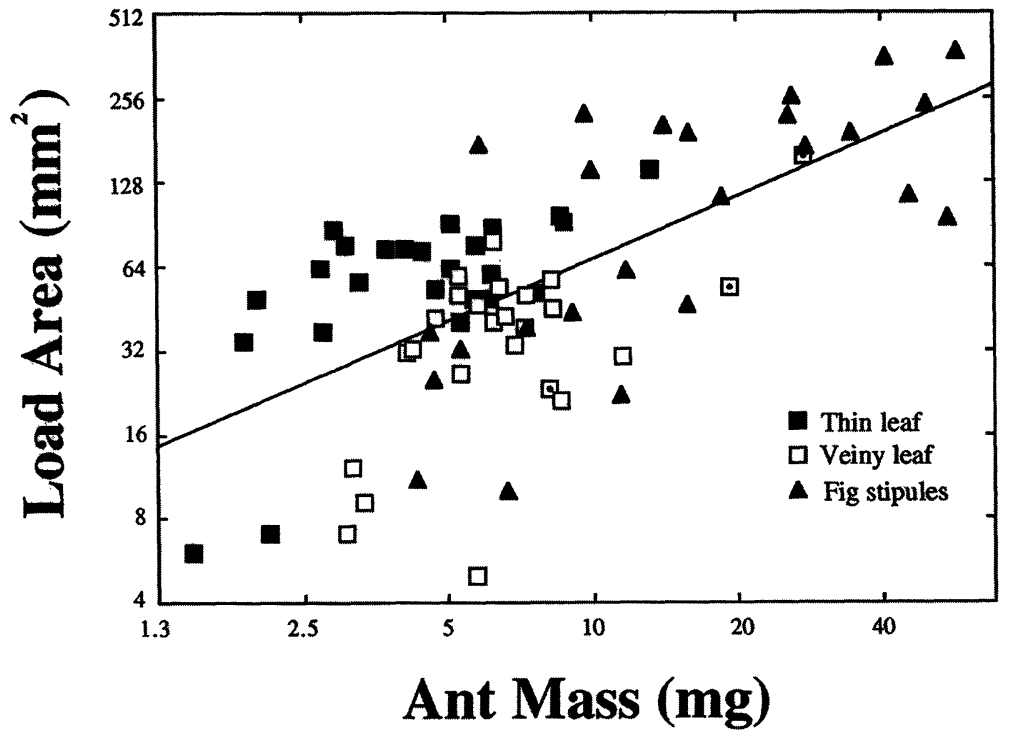

Figure 2. Load area selection by Atta colombica foragers. The logarithmic relationship between ant mass $\left(m_{\mathrm{A}}\right.$ in $\left.\mathrm{mg}\right)$ and load area $\left(\alpha\right.$ in $\left.\mathrm{mm}^{2}\right)$. The line is the least squares linear regression for the 75 foragers from colony A with vegetation fragments. Equation given in text. Symbols as in Fig. 1. 
mg. Mean burden was $8.3 \pm 3.0$. Burden ranged from 3.8 for the largest ant to 12.3 for the smallest ant.

The maximum burden of 12.3 is higher than the maximum observed for A. colombica foragers carrying vegetation fragments. Foragers appear to be capable of carrying such heavy burdens only when the load is compact like a berry or a flower bud; very large leaf fragments appear to be more difficult to balance (pers. obs.). If the maximum burden possible for A. colombica foragers is approximately 12 times body mass, then only workers larger than $14 \mathrm{mg}$ would be able to carry even the smallest of the whole berries. Workers smaller than $14 \mathrm{mg}$ would have to cut fragments from the berries in order to be able to carry the load.

Largest maxima workers

Of the very large unladen A. colombica workers I collected from several colonies around BCI, the largest weighed $58.9 \mathrm{mg}$ and had a head width of $4.6 \mathrm{~mm}$. This mass was only slightly greater than the largest laden forager I collected at colony A $(56.8 \mathrm{mg})$. These maximum values are approximately equal to or greater than those previously reported $(35 \mathrm{mg}$ - Weber 1968; $60 \mathrm{mg}$ - Lighton et al. 1987; $4.2 \mathrm{~mm}$ - Borgmeier 1959). The largest A. colombica in the MCZ collection had a head width of $4.2 \mathrm{~mm}$.

The largest A. cephalotes worker I have measured weighed approximately $110 \mathrm{mg}$ (Wetterer unpublished) and the largest in the MCZ collection had a head width of $6.4 \mathrm{~mm}$. These maximum values are equal to or greater than those previously reported (103 mg - Weber 1968; 6.1 mm - Stradling 1978; $6.4 \mathrm{~mm}$ - Borgmeier 1959).

\section{General observations}

I found A. colombica on BCI foraging almost exclusively during the day, with very few ants returning to the nest with loads after early evening. All A. colombica colonies I observed had external refuse dumps. I found that the ants removed refuse from the nests day and night, as reported by Hodgson (1955).

A. colombica appeared to have foraging trails that were more branching than A. cephalotes, simultaneously attacking greater numbers of different vegetation sources. Trails often fanned out through the forest floor to cut crops of fallen leaves, flowers, stipules, sepals, and fruit. I commonly found large A. colombica foragers 
cutting crops of fallen fig fruits (also see Weber, 1969). This contrasts with Shepherd's (1985) finding of little ground foraging in A. colombica in Colombia.

Species identification

Several dozen $A$. cephalotes and A. colombica specimens in the ant collection at the Museum of Comparative Zoology (MCZ) at Harvard University were found to be misidentified (pers. obs.; J. Longino, pers. comm.). It seems very likely that some of the published field studies of A. cephalotes and A. colombica may have also confused the identification of these two species.

\section{DISCUSSION}

I found that the size-range of workers participating in foraging was broader for A. colombica $(1.5-56.8 \mathrm{mg})$ than for A. cephalotes (1.4-32.1 mg; Wetterer 1990a, 1994). Overall, 13\% of the A. colombica foragers attacking the three vegetation sources weighed $24 \mathrm{mg}$ or more (Table 1). Whether this small sample of vegetation sources is representative of what A. colombica foragers generally harvest is unknown. However, Lighton et al. (1987), studying the energetics of $A$. colombica foragers on BCI, similarly found $13 \%$ (20/154) of the foragers weighed $24 \mathrm{mg}$ or more (Table 1). In Lighton et al.'s (1987) study, mean forager mass was $15.2 \pm 7.1 \mathrm{mg}$ (range 3.6 to $35.6 \mathrm{mg} ; \mathrm{n}=154$ ). This size-distribution is intermediate for A. colombica attacking the two denser vegetation sources in the present study.

In A. cephalotes, the largest workers (24-100 mg) rarely forage (Wetterer, 1990a; 1994). Instead, the largest A. cephalotes workers appear to function primarily as soldiers, guarding the nest. In two field studies of $A$. cephalotes, I found less than $1 \%$ of the foragers weighed more than $24 \mathrm{mg}$ (Table 1; data from Wetterer 1990a, $\mathrm{n}=$ 1100; and Wetterer 1994, $\mathrm{n}=900$ ). In my 1994 study, the range of densities of 18 trees attacked by A. cephalotes was 0.15 to 0.37 $\mathrm{mg} / \mathrm{mm}^{2}$. This appears to be representative of the range of densities of tree leaves typically cut by A. cephalotes, though on occasion they attack denser sources, e.g., Rudolph and Loudon (1986) observed A. cephalotes attacking the leaves of an epiphyte with a density of $0.58 \mathrm{mg} / \mathrm{mm}^{2}$. The maxima workers of $A$. cephalotes are larger and appear to be more specialized as soldiers than the maxima 
workers of A. colombica. Wilson (1984) found a similar trend in species of Pheidole where increased specialization of maxima workers was correlated with increased maxima to minima sizeratio, as predicted by caste optimization theory (see Oster and Wilson, 1978).

In both A. colombica and A. cephalotes, larger foragers cut at denser, tougher vegetation sources and cut the denser, tougher parts of individual sources (Cherrett, 1972; Rudolph and Loudon, 1986; Nichols-Orians and Schultz, 1989; Wetterer 1990b, 1991a, 1994, present study: Table 1, Fig. 3). This match of ant mass to vegetation toughness and specific density appears to increase the efficiency of both cutting (Wilson, 1980) and load delivery (Wetterer, 1994). High specific density and toughness can prevent successful foraging in A. cephalotes (Nichols-Orians and Schultz, $1989,1990)$. The broader size-range of $A$. colombica foragers may allow them to exploit efficiently a wider range of resources than

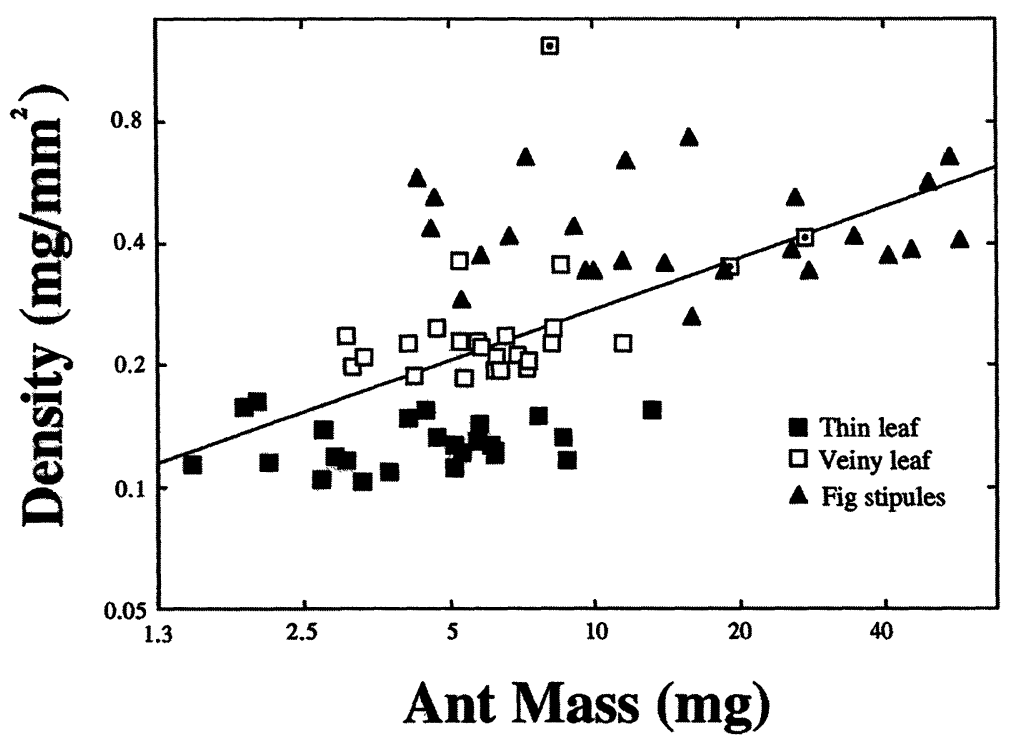

Figure 3. Load density selection by Atta colombica foragers. The logarithmic relationship between ant mass $\left(m_{\mathrm{A}}\right.$ in $\left.\mathrm{mg}\right)$ and load specific density $\left(\delta \mathrm{in} \mathrm{mg} / \mathrm{mm}^{2}\right)$. The line is the least squares linear regression for the 75 foragers from colony $\mathrm{A}$ with vegetation fragments. Equation given in text. Symbols as in Fig. 1. 
A. cephalotes. Indeed, Rockwood (1976) found that A. colombica harvested a wider range of plant species than $\operatorname{did} A$. cephalotes. The larger foragers of $A$. colombica may allow more successful exploitation of tough resources such as leaf stipules. Large $A$. colombica foragers also may be important in cutting through the thick tough skin of some fruits, such as figs, making the flesh of the fruit available to smaller foragers (pers. obs.).

A. colombica foragers cutting from thick and veiny leaf sources showed a reduction in fragment area cut (Table 2, Fig. 2). A. cephalotes foragers show similar reductions under some circumstances, particularly when there is a mismatch between forager size and vegetation source, i.e., when small ants cut very dense vegetation (Wetterer, 1990a; 1994; Roces and Hölldobler, 1994). In A. cephalotes, this reduction can be due to many factors including large workers finishing cuts abandoned by smaller workers, large workers taking oversize loads away from smaller workers (Rudolph and Loudon, 1986; Wetterer, 1990a; 1994), and active changes in cutting behavior (Roces and Hölldobler, 1994). In the present study, there is no information as to the mechanism of the reduction.

The maxima foragers of $A$. colombica not only appear to have greater cutting abilities, they also can carry heavier loads (Fig. 1). This can be a particular advantage when harvesting resources such as berries (Table 1, Fig. 1). For possibly similar reasons, Acromyrmex octospinosus and Acromyrmex volcanus, two species of leaf-cutting ants that depend largely on cutting or collecting fallen fruit, flowers and other vegetation, have very large foragers, large enough to cut or collect any desirable vegetation encountered (Wetterer, 1991b; 1993). In addition to advantages that may result from the use of very large workers as foragers, there are also substantial costs. Larger workers are energetically more expensive to produce than smaller workers, and foragers are generally exposed to greater mortality risks than workers that remain in the nest. Also, parasitic phorid flies preferentially attack larger Atta foragers (Orr, 1992), making the maxima foragers particularly vulnerable.

A. colombica and A. cephalotes show other ecological differences. On BCI and on the Osa Peninsula in Costa Rica, A. colombica are primarily diurnal foragers year-round, whereas $A$. cephalotes forage primarily during the day in the wet season and 
primarily during the night in the dry season (Lugo et al., 1973; Feener and Moss, 1990; Orr, 1992). (The observation of diurnal foraging during the dry season suggests that the A. "cephalotes" colony studied by Lutz (1929) on BCI may have been actually an A. colombica colony.) Rockwood (1975), however, found that although A. colombica in Guanacaste, Costa Rica, foraged primarily during the day, they also showed significant foraging at night.

A. cephalotes at La Selva Biological Station in Costa Rica also shift from primarily diurnal foraging in the wet season to primarily nocturnal foraging in the dry season (Wetterer, 1990a). Wetterer (1990a) proposed that this shift could be a mechanism for avoidance of parasitism by diurnal phorid flies that are active in the dry season. At La Selva, however, phorids known to attack $A$. cephalotes appear to be, if anything, more active in the wet season (B. Brown pers. comm.; also see Feener and Brown, 1993). Orr (1992) similarly proposed that avoidance of phorids could explain the differences between the foraging of A. colombica and $A$. cephalotes on the Osa Peninsula, because at this site phorids were found only attacking $A$. cephalotes. However, the same pattern of foraging also occurs on BCI, where diurnal phorids heavily attack A. colombica foragers (Feener and Moss, 1990).

The phorid flies' differential attack of $A$. colombica and $A$. cephalotes suggests that the pheromones of the two Atta species differ. Interestingly, A. sexdens may be easily distinguished from A. colombica and A. cephalotes by the strong lemon-like smell of crushed A. sexdens workers (pers. obs.). Brown and Feener (1991) proposed that phorids that use olfactory cues to find their hosts may be important in the evolution of pheromone diversity in ants. What role parasitic phorids might play in the distribution, ecology, and evolution of A. colombica and A. cephalotes deserves further attention.

A. colombica is the only Atta species for which external refuse dumps have been reported in the literature (Haines, 1978). Stefan Cover (pers. comm.), however, has noted such refuse dumps outside Atta colonies in Trinidad (the Trinidad species is currently classified as A. cephalotes, but may be a separate species, J. Longino pers. comm.; also see Borgmeier, 1950). Fowler (1985) found external refuse dumps in the Paraguayan leaf-cutting ants Acromyrmex lundi pubescens and Acromyrmex landolti. Neither of 
these taxa have any other obvious similarities with A. colombica. Ac. lundi pubescens is found both in forests and in open habitats and harvests the leaves of dicots, whereas Ac. landolti is found only in open habitats and harvests grass (Fowler, 1985). The ecological significance of external refuse dumps remains a mystery (see Haines, 1978; 1983 for further discussion).

Further studies are needed to evaluate the ecological differences between A. colombica and A. cephalotes. In these studies, it is essential to keep voucher species from each colony under study in order to verify species identification.

\section{ACKNOWLEDGMENTS}

I thank M. Wetterer, J. Longino, A. Lazarus, D. Feener, and B. Brown for comments on this manuscript. Financial support was provided by the National Geographic Society, the National Science Foundation (BSR 91-03782), the Smithsonian Tropical Research Institute, Harvard University, and Wheaton College. I thank M. Morello, G. Maggiori, M. Vargas, C. Kolman, and S. Cover for their kindness and help.

\section{Literature Cited}

Borgmeier, O.F.M. 1950. Estudos sôbre Atta (Hym. Formicidae). Mem. Instit. Oswaldo Cruz 48:239-292.

1959. Revision der Gattung Atta Fabricius (Hymenoptera, Formicidae). Studia Entomol. 2:321-390.

Brown, B.V., and D.H. Feener, Jr. 1991. Behavior and host location cues of Apocephalus paraponerae (Diptera: Phoridae), a parasitoid of the giant tropical ant, Paraponera clavata (Hymenoptera: Formicidae). Biotropica 23:182-187.

Cherrett, J.M. 1972. Some factors involved in the selection of vegetable substrate by Atta cephalotes (L.) (Hymenoptera: Formicidae) in tropical rain forest. J. Anim. Ecol. 41:647-660

Emery, C. 1913. Études sur les Myrmicinæ. VI. Les espèces d'Atta. Ann. Soc. Entomol. Belg. 57:255-261.

1922. Hymenoptera, fam. Formicidae, subfam. Myrmicinae. In P. Wytsman (Ed.). Genera Insectorum, no. 174. p. 330-355. Louis Desmet-Verteneuil, Brussels.

Feener, D.H. Jr., and B.V. Brown. 1993. Oviposition behavior of an ant-parasitizing fly, Neodohrniphora curvinervis (Diptera: Phoridae), and defense behavior by its leaf-cutting ant host Atta cephalotes (Hymenoptera: Formicidae). J. Insect Behav. 6:675-688..

Feener, D.H. Jr., and K.A.G. Moss. 1990. Defense against parasites by hitchhikers in leaf-cutting ants: a quantitative assessment. Behav. Ecol. Sociobiol. 26:17-29. 
Fowler, H.G. 1985. Leaf-cutting ants of the genera Atta and Acromyrmex of Paraguay (Hymenoptera Formicidae). Deut. Entomol. Z. 32:19-34.

Haines, B.L. 1978. Element and energy flow through colonies of the leaf-cutting ant, Atta colombica, in Panama. Biotropica 10:270-277.

1983. Leaf-cutting ants bleed mineral elements out of rain forest in southern Venezuela. Trop. Ecol. 24:85-93.

Hodgson, E.S. 1955. An ecological study of the behavior of the leaf-cutting ant Atta cephalotes. Ecology 36:293-304.

Kempf, W.W. 1972. Catálogo abreviado das formigas da região neotropical (Hymenoptera: Formicidae). Studia Entomol. 15:3-344.

Lighton, J.R.B., D.H. Feener Jr., and G.A. Bartholomew. 1987. Energetics of locomotion and load carriage and a model of the energy cost of foraging in the leafcutting ant Atta colombica Guer. Physiol. Zool. 60:524-537.

Lugo, A.E., E.G. Farnworth, D. Pool, P. Jerez, and G. Kaufman. 1973. The impact of the leaf cutter ant Atta colombica on the energy flow of a tropical wet forest. Ecology 54:1292-1301.

Lutz, F.E. 1929. Observations on leaf-cutting ants. Amer. Mus. Nov. 388:1-21.

Mackay, W., and E. Mackay. 1986. Las hormigas de Colombia: arrieras del género Atta (Hymenoptera: Formicidae). Rev. Colomb. Entomol. 12:23-30.

Nichols-Orians, C.M., and J.C. Schultz. 1989. Leaf toughness affects leaf harvesting by the leaf-cutter ant, Atta cephalotes (L.) (Hymenoptera: Formicidae). Biotropica 21:80-83.

1990. Interactions among leaf toughness, chemistry, and harvesting by attine ants. Ecol. Entomol. 15:311-320.

Orr, M.R. 1992. Parasitic flies (Diptera: Phoridae) influence foraging rhythms and caste division of labor in the leaf-cutter ant, Atta cephalotes (Hymenoptera: Formicidae). Behav. Ecol. Sociobiol. 30:395-402

Oster, G.F. and E.O. Wilson. 1978. Caste and ecology in the social insects. Princeton University Press, Princeton.

Roces, F., and B. Hölldobler. 1994. Leaf density and a trade-off between load-size selection and recruitment behavior in the ant Atta cephalotes. Oecol. 97:1-8.

Rockwood, L.L. 1973. Distribution, density, and dispersion of two species of Atta (Hymenoptera: Formicidae) in Guanacaste Province, Costa Rica. J. Anim. Ecol. 42:803-817.

1975. The effects of seasonality on foraging in two species of leaf-cutting ants (Atta) in Guanacaste, Costa Rica. Biotropica 7:176-193.

1976. Plant selection and foraging patterns in two species of leaf-cutting ants (Atta). Ecology 57:48-61.

Rudolph, S.G., and K. Loudon. 1986. Load size selection by foraging leaf-cutter ants (Atta cephalotes). Ecol. Entomol. 11:401-410.

Shepherd, J.D. 1985. Adjusting foraging effort to resources in adjacent colonies of the leaf-cutter ant, Atta colombica. Biotropica 17:245-252.

Stradling, D.J. 1978. The influence of size on foraging in the ant, Atta cephalotes, and the effect of some plant defense mechanisms. J. Anim. Ecol. 47:173-188.

Vasconcelos, H.L. 1990. Foraging activity of two species of leaf-cutting ants (Atta) in a primary forest of the central Amazon. Insectes Soc. 37:131-145.

Weber, N.A. 1968. The Panamanian Atta species. Proc. Entomol. Soc. Wash. 70:348-350. 50:141-147.

1969. Ecological relations of three Atta species in Panama. Ecology 
1972. Gardening ants: the attines. American Philosophical Society. Philadelphia, Pennsylvania.

Wetterer, J.K. 1990a. Diel changes in forager size, activity, and load selectivity in a tropical leaf-cutting ant, Atta cephalotes. Ecol. Entomol. 15:97-104.

1990b. Load-size determination in leaf-cutting ants. Behav. Ecol. 1:95-101.

1991a. Allometry and the geometry of leaf-cutting in Atta cephalotes. Behav. Ecol. Sociobiol. 29:347-351.

1991b. Foraging ecology of the leaf-cutting ant, Acromyrmex octospinosus, in a Costa Rican rain forest. Psyche 98:361-371.

1993. Foraging and nesting ecology of a Costa Rican leaf-cutting ant, Acromyrmex volcanus. Psyche 100:65-76.

1994. Forager polymorphism, size-matching, and load delivery in the leaf-cutting ant, Atta cephalotes. Ecol. Entomol. 19:57-64.

Wilson, E.O. 1980. Caste and division of labor in leaf-cutter ants. II. The ergonomic optimization of leaf cutting. Behav. Ecol. Sociobiol. 7:157-165.

1984. The relation between caste ratios and division of labor in the ant genus Pheidole (Hymenoptera: Formicidae). Behav. Ecol. Sociobiol. 16:89-98.

1986. The defining traits of fire ants and leaf-cutting ants. In C.S. Lofgren and R.K. Vander Meer (Eds.). Fire Ants and Leaf-cutting Ants. Biology and Management, p. 1-9, Westview Press, Boulder, CO. 

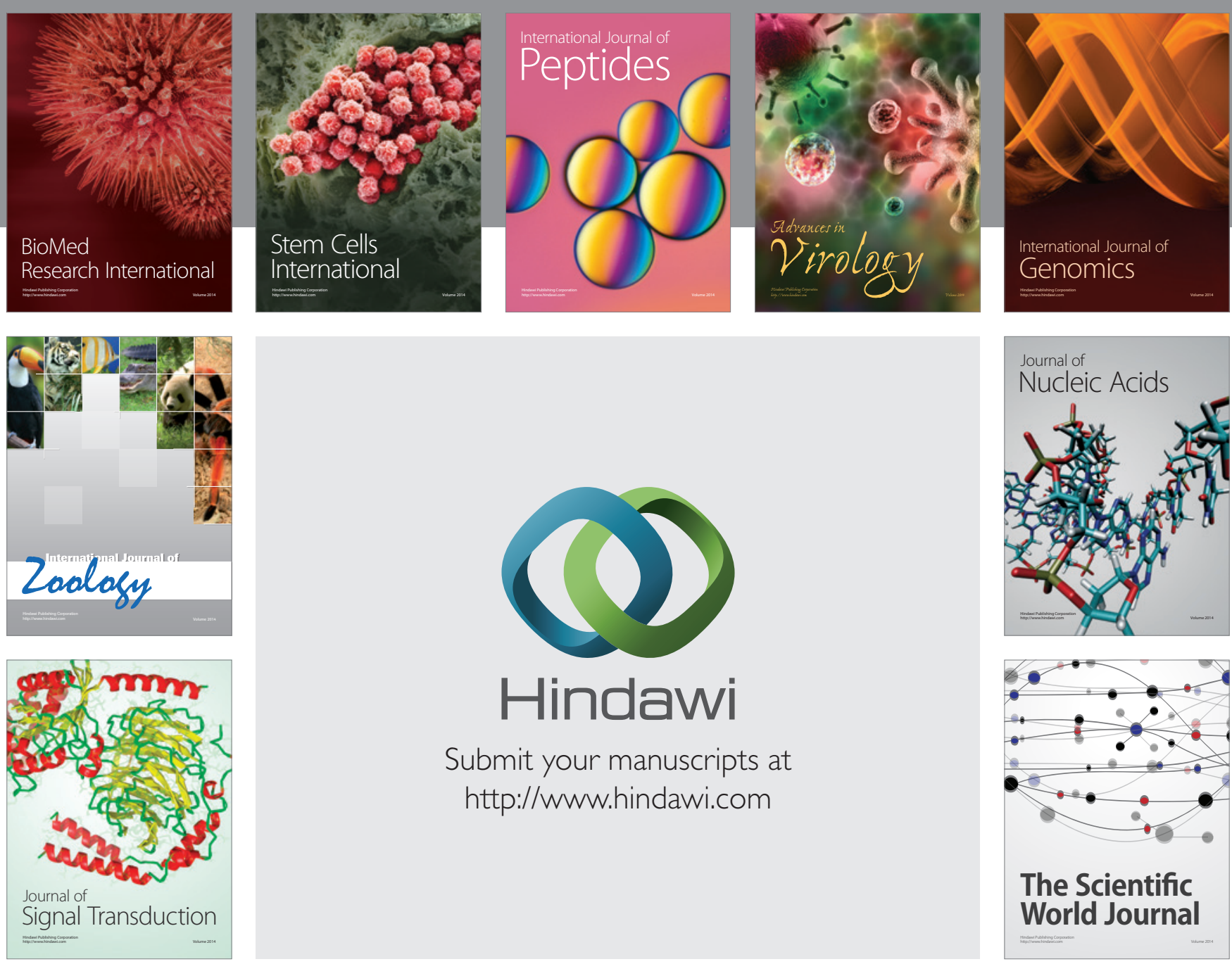

Submit your manuscripts at

http://www.hindawi.com
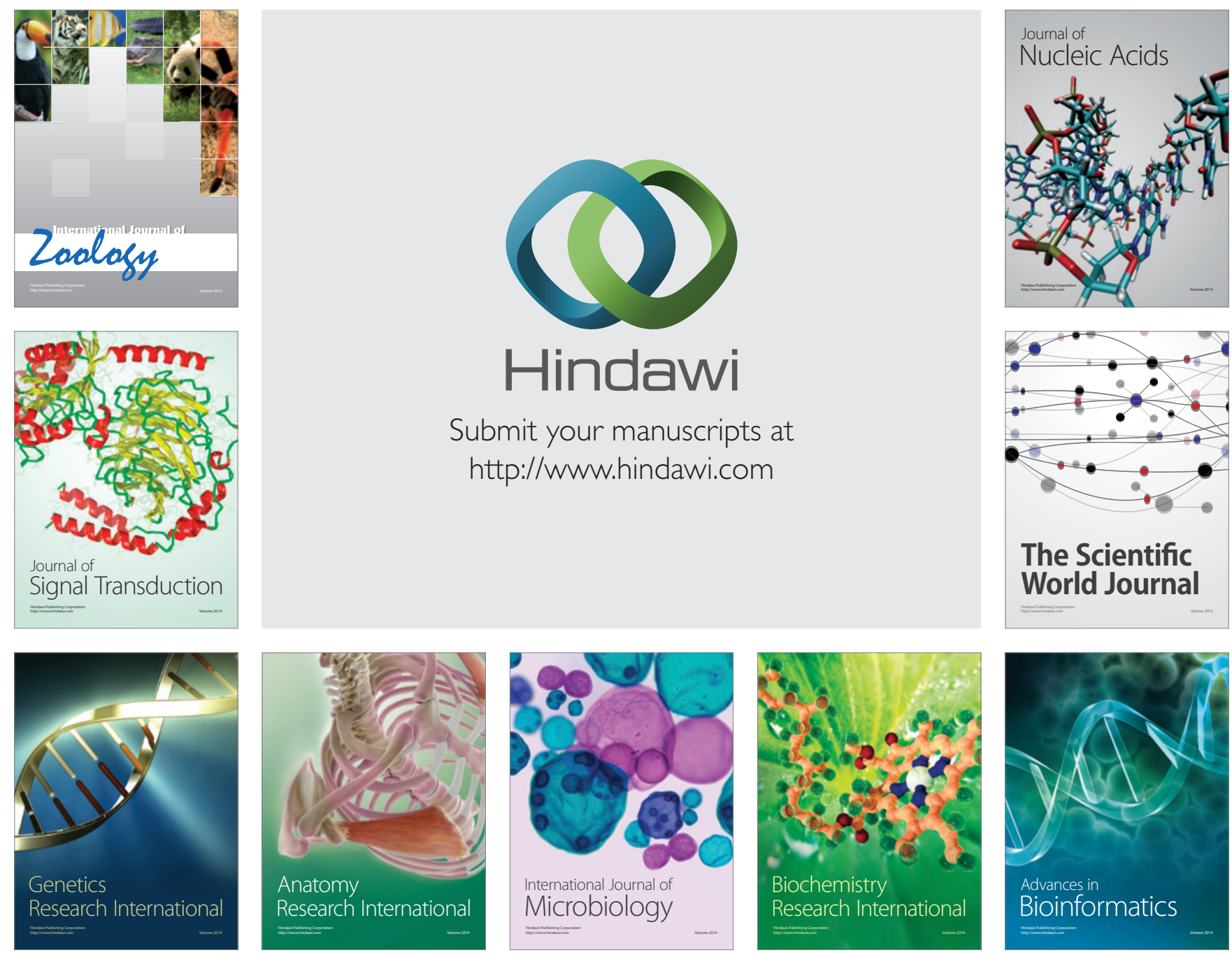

The Scientific World Journal
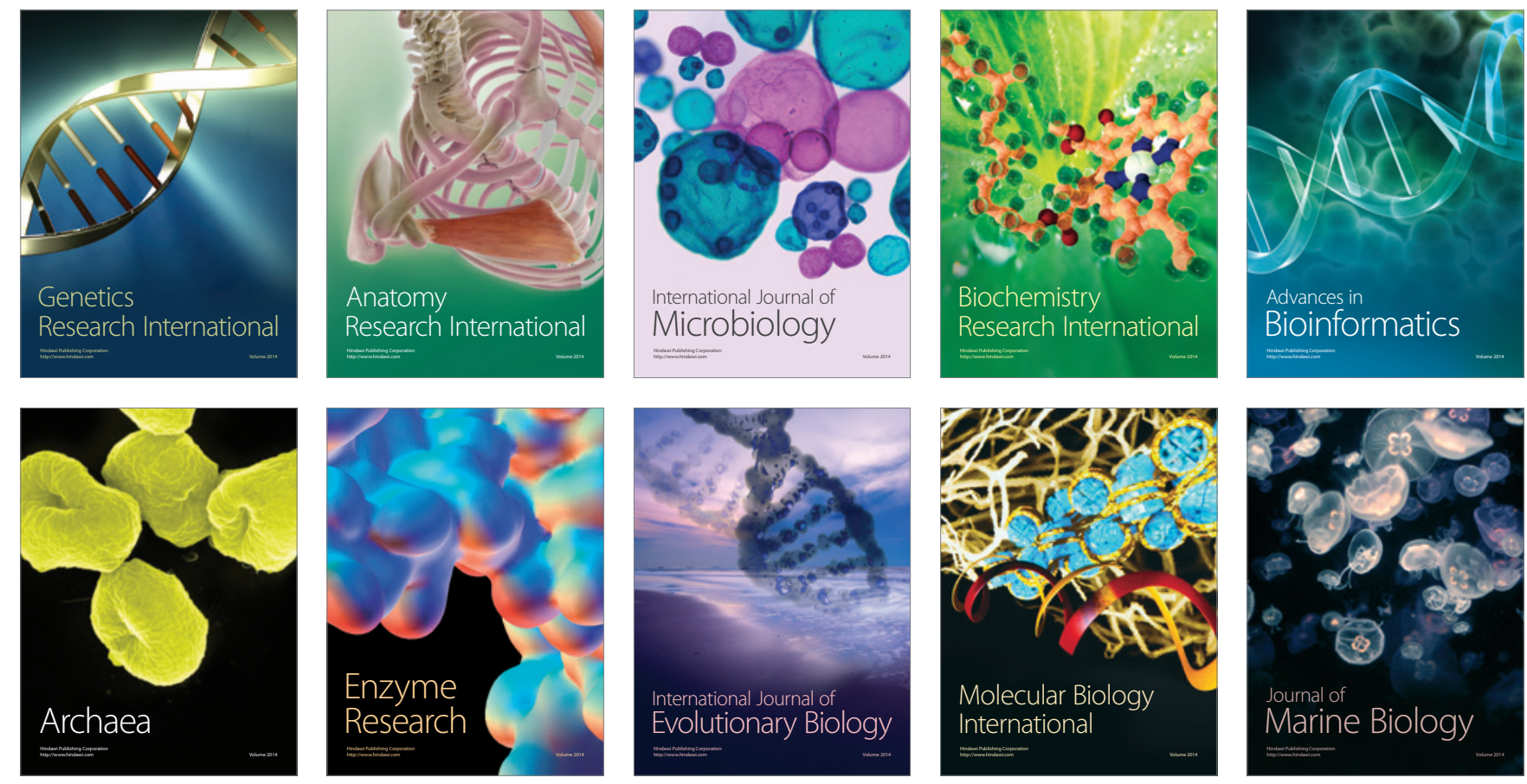